This is an author produced version of a paper published in Clinical Implant Dentistry and Related Research. This paper has been peer-reviewed but does not include the final publisher proof-corrections or journal pagination.

Citation for the published paper:

Chrcanovic, Bruno; Kisch, Jenö; Albrektsson, Tomas; Wennerberg, Ann. (2018). Factors influencing the fracture of dental implants. Clinical Implant Dentistry and Related Research, vol. 20, issue 1, p. null

URL: https://doi.org/10.1111/cid.12572

Publisher: Wiley

This document has been downloaded from MUEP (https://muep.mah.se) / DIVA (https://mau.diva-portal.org). 


\section{Factors influencing the fracture of dental implants}

Running head: Risk factors for implant fracture

Bruno Ramos Chrcanovic ${ }^{1 *}$, Jenö Kisch ${ }^{2}$, Tomas Albrektsson ${ }^{3}$, Ann Wennerberg ${ }^{4}$

${ }^{1}$ DDS, MSc, PhD student; Department of Prosthodontics, Faculty of Odontology, Malmö University, Malmö, Sweden

${ }^{2}$ DDS, OD. h.c.; Clinic for Prosthodontics, Centre of Dental Specialist Care, Malmö, Sweden

3 MD, PhD, RCPSG; Department of Biomaterials, Göteborg University, Göteborg, Sweden; Department of Prosthodontics, Faculty of Odontology, Malmö University, Malmö, Sweden

${ }^{4}$ DDS, PhD; Department of Prosthodontics, Faculty of Odontology, Malmö University, Malmö, Sweden

* Corresponding author:

Bruno Ramos Chrcanovic, Department of Prosthodontics, Faculty of Odontology, Malmö University, Carl Gustafs väg 34, SE-214 21, Malmö, Sweden. bruno.chrcanovic@mah.se; brunochrcanovic@hotmail.com Mobile: +46 725541545 Fax: +46 406658503

Bruno Ramos Chrcanovic, Jenö Kisch, Tomas Albrektsson, Ann Wennerberg: no conflict of interest

Author contributions

Bruno Ramos Chrcanovic: concept/design, data collection/acquisition, statistics, data analysis/interpretation, drafting article, critical revision of article, approval of article, agreed to be accountable for all aspects of the work.

Jenö Kisch, Tomas Albrektsson, Ann Wennerberg: concept/design, data analysis/interpretation, critical revision of article, approval of article, agreed to be accountable for all aspects of the work. 


\section{Abstract}

Background. Implant fractures are rare but offer a challenging clinical situation.

Purpose. To determine the prevalence of implant fracture and the possible risk factors predisposing an implant to a higher fracture risk.

Materials and Methods. This retrospective study is based on 2,670 patients consecutively treated with implant-supported prostheses. Anatomical-, patient-, and implant-related factors were collected. Descriptive statistics and survival analyses were performed. Generalized estimating equations (GEE) evaluated the effect of explanatory variables on implant fracture.

Results. Forty-four implants (out of 10,099; 0.44\%) fractured. The mean \pm SD time for fracture to occur was $95.1 \pm 58.5$ months (min-max, 3.8-294.7). Half of the occurrences of fracture happened between 2 and 8 years after implantation. Five factors had a statistically significant influence on the fracture of implants (increase/decrease in fracture probability): use of higher grades of titanium (decrease 72.9\%), bruxism (increase 1,819.5\%), direct adjacency to cantilever (increase 247.6\%), every $1 \mathrm{~mm}$ increase in implant length (increase 22.3\%), every $1 \mathrm{~mm}$ increase in implant diameter (decrease 96.9\%).

Conclusions. It is suggested that five factors could influence the incidence of implant fractures: grade of titanium, implant diameter and length, cantilever, bruxism.

Keywords. Higher grades of Ti; implant fracture; risk factors; logistic models; multivariate analysis 


\section{Introduction}

Knowledge regarding the types of complications that can occur in dental implant oral rehabilitations is an important aspect of the post-treatment care. Among the mechanical complications, implant fractures offer a challenging situation because of their functional, restorative, surgical, and emotional implications. ${ }^{1}$ Implant fracture is the most catastrophic failure of implant components because it usually causes the loss of the implant and prosthesis. ${ }^{2}$ Fortunately, implant fractures do not occur as frequently as abutment screw or prosthesis gold screw fractures. ${ }^{3,4}$ Implant fractures were first described by Brånemark et al. ${ }^{5}$ in 1977, who reported on 13 fractured implants on a total of 1,618 osseointegrated implants. The prevalence in several studies altogether is reported to be around $1.0-1.5 \%$ according to two review papers, ${ }^{1,4}$ mostly considering older turned Brånemark implants made from grade 1 titanium. A study of 157 ITI implants (Straumann AG, Waldenburg, Switzerland) that were followed up for a mean of 40 months reported a $1.9 \%$ fracture rate. ${ }^{6}$

The aim of the present retrospective clinical study was to determine the prevalence of implant fracture and to determine the possible risk factors predisposing an implant to a higher fracture risk.

\section{Materials and Methods}

Materials. This retrospective study is based on all 2,670 patients who received 10,099 implants, and were consecutively treated with implant-supported prostheses between 1980 and 2014 at one specialist clinic (Clinic for Prosthodontics, Centre of Dental Specialist Care, Malmö, Sweden). The study was approved by the Regional Ethical Review Board in Lund (Dnr 2014/598; Dnr 2015/72). This study is in concordance with the STROBE guidelines for observational studies.

As the standard protocol in the clinic, the patients' dental hygiene was followed up by a dental hygienist within 6 months after the final implant-supported/retained restoration. Each patient then attended a dental hygiene recall program based on individual needs. 
Definitions. An implant was considered fractured when a fracture line was running through the implant only. Fractures of the abutment or other prosthetic parts were not considered as a fractured implant.

Relation of an implant and a cantilever in the prosthetic work: (a) implant adjacent to a cantilever; (b) implant is distant one tooth away from the cantilever; (c) implant is distant two teeth away from the cantilever (Figure 1); (d) half-cantilever (implant is adjacent to a prosthetic cantilever, but this is approximately half the length of an one-tooth prosthetic element); (e) there is no cantilever or implant is distant three or more teeth away from the cantilever ("no cantilever").

Inclusion and exclusion criteria. Only modern endosseous dental implants with cylindrical or conical design were considered. Zygomatic implants were not included in the study, as well as implants detected in radiographies, but without basic information about them in the patients' files.

Data collection. The dental records of all patients ever treated with implants in the aforementioned clinic were read in order to collect the data. The data were directly entered into a SPSS file (SPSS software, version 23, SPSS Inc., Chicago, IL, USA) as the files were being read. The following data were collected: grade of titanium - turned (machined) Brånemark implants were made from grade 1 titanium, whereas all other implants of the present study were made from grade 3 or 4 titanium (Nobel MKIII TiUnite, Nobel Active, Astra TiOblast, Astra Osseospeed, Straumann SLA, Straumann Bone Level, XIVE, Frialit-2, Begos Semados, other), implant length and diameter, implant design (cylindrical or conical), bone graft procedures, implant jaw location (maxilla or mandible), anterior or posterior location of the implant (locations between teeth 13-23 and between 33-43 were considered anterior location), number of implants in maxilla/mandible, type of implantsupported prosthetic restoration (single crown, partial bridge with 2-6 prosthetic elements, partial bridge with 7-10 prosthetic elements, full-arch, overdenture), prosthetic connection of implants to teeth, presence of cantilever in the prosthetic work (see definitions above), patient's sex, age of the patient at the implant insertion surgery, number of days until failure, follow-up time. Bone quantity and quality of the treated jaws were classified at the time of surgery according to the Lekholm and 
$Z^{Z a r b}{ }^{7}$ classification. The intake of antidepressants, smoking habits, and the presence of bruxism were also considered. In order to diagnose patients as bruxers, the authors followed the definition of bruxism proposed by Lobbezoo et al., ${ }^{8}$ and the sign and symptoms of bruxism were listed according to the International Classification of Sleep Disorders, ${ }^{9}$ following the same guidelines used in a clinical study. ${ }^{3}$

Statistical analyses. The mean, standard deviation (SD), and percentages were presented as descriptive statistics. Kolmogorov-Smirnov test was performed to evaluate the normal distribution of the variables, and Levene's test evaluated homoscedasticity. The performed tests for two independent groups were Student's t-test or Mann-Whitney test, and paired-samples $t$-test or Wilcoxon signed-rank test for two dependent groups, depending on the normality. Pearson's chisquared or Fisher's exact test was performed for categorical variables, depending on the expected count of events in a $2 \times 2$ contingency table.

An implant-level model having the implant as the statistical unit was performed in order to assess the effects of the implant-related and local bone factor on the failure of implants to the fracture of implants. A generalized estimating equation (GEE) method was used to account for the fact that repeated observations (several implants) were available for a single patient. All models were adjusted for clustering of subject and implants in a binary logistic regression model using GEE with a binomial distribution and a logit link function, while assuming an exchangeable working correlation structure to assess the relationship between implant fracture (dependent variable) and the risk factors (independent variables). In order to verify multicollinearity, a correlation matrix of all of the predictor variables was scanned, to see whether there were some high correlations among the predictors. Collinearity statistics obtaining variance inflation factor (VIF) and tolerance statistic were also performed to detect more subtle forms of multicollinearity. A GEE model with a forced entry method was used to evaluate the effect of the factors on implant fracture. A Wald chi-square test was used to analyze the statistical significance of each parameter within the model. The results of the final model were presented as an estimated OR of each significant prognostic variable $(p<0.05)$. 
Survival analyses were performed. A life table was presented with cumulative survival rate (CSR), besides Kaplan-Meier curves. All data were statistically analyzed using the Statistical Package for the Social Sciences (SPSS) version 23 software (SPSS Inc., Chicago, IL, USA).

\section{Results}

There were 44 implant fractures (out of 10,099 implants; $0.44 \%$ ). The fractured implants were 30 Nobel Brånemark turned (out of 5,748; 0.52\%), 6 Straumann SLA (out of 285; 2.11\%), 4 Astra TiOblast (out of 391, 1.02\%), 3 Astra Osseospeed (out of 210, 1.43\%), and 1 Nobel MKIII TiUnite (out of $2,783,0.04 \%)$. Straumann SLActive and Roxolid implants accounted for only 11 implants and did not present fractures, but they were followed up for shorter periods of time (19.5 \pm 14.6 months). Straumann Bone Level and Bego Semados implants accounted for 39 and 152 implants, respectively, and did not present fractures (mean follow-up of $50.9 \pm 20.5$ and $49.2 \pm 23.6$ months, respectively). Only Astra Osseospeed implants with internal hexagon had fractures located at prosthetic (the most coronal) part of the implant. All other implants systems presented transversal fracture along the implant body, in the threaded area. Twenty-three out of 44 fractured implants occurred in fixed fullarch restorations, 6 in single crowns, 6 in 3-unit fixed partial prosthesis (FPP), 4 in 4-unit FPP, 2 in 5unit FPP, 2 in overdentures, and 1 implant fracture in a 7-unit FPP. Table 1 shows the distribution of implant types with respect to the different kinds of prosthetic restorations. Turned grade 1 and enlarged-surface grade 3-4 titanium implants were followed up for a mean \pm SD of $155.5 \pm 89.1$ (min$\max , 1-437.5)$ and 77.4 \pm 51.6 months (min-max, 0-279.1), respectively $(p<0.01$, Mann-Whitney test). All fractured implants had a cylindrical design (44 out of 9,609, $0.46 \%$ ), however, the number of tapered/conical implants were far fewer $(n=447)$ than the cylindrical ones. Only 41 implants were placed into fresh extraction sockets, of which only one fractured. Implants placed in the premolar region were more often adjacent to a cantilever (39.9\%) than implants placed in other tooth regions (Table 2). The fractured implants were located in teeth sites of incisors $(13 / 3,738 ; 0.35 \%)$, canines $(12 / 2,355 ; 0.51 \%)$, premolars $(18 / 3,303 ; 0.54 \%)$, and molars $(1 / 703 ; 0.14 \%)$. The mean \pm SD time for 
fracture to occur was $95.1 \pm 58.5$ months (min-max, 3.8-294.7). Table 3 shows the distribution of implants and fractures according to different implant diameter ranges. The highest implant fracture rate occurred among implants of narrow diameter $(3.00-3.50 \mathrm{~mm})$ with $1.35 \%$, followed by the implants of regular diameter $(3.70-4.10 \mathrm{~mm})$ with $0.34 \%$. No implant fracture was observed in implants of wide diameter (4.20-5.00 mm). All fractures but one that were noticed among "average sized" implants of a diameter of 3.7-4.10 mm occurred with Titanium grade 1 machined implants of which 29 fractured, equivalent to $0.52 \%$ of all machined implants. The single average sized implant that also fractured was a Nobel MK III TiUnite design, but this fracture represented 1 implant out of 2,631 TiUNite ones, i.,e, a fracture frequency of only $0.04 \%$. Straumann SLA implants presented by far the highest fracture rate (7.31\%) among implants of narrow diameter (3.00-3.50 mm). Modern grade 3-4 implants may be said to mainly fracture when implants are of a narrow diameter since 13 of a total of 14 fractures among these brands occurred in implants of narrow diameter.

According to the GEE model (Table 4), five factors had a statistically significant influence on the fracture the implants: grade of titanium, implant diameter, implant length, prosthetic work with cantilever, and bruxism. Titanium grade $3-4$ implants had $72.9 \%$ less probability of fracture than turned, grade 1 implants. Bruxers had a 1,819.5\% higher probability of presenting an implant fracture in comparison to non-bruxers. The presence of a cantilever increases a chance of fracture by $247.6 \%$ for implants adjacent to it, in comparison to implants distant at least 3 teeth-length away from the cantilever or with no cantilever. Moreover, every $1 \mathrm{~mm}$ increase in implant diameter decreases the probability of fracture by $96.9 \%$ and every $1 \mathrm{~mm}$ increase in implant length increases the probability of fracture by $22.3 \%$. Considering the statistically significant influence of implant diameter and length on implant fracture, the mean and standard deviation diameter and length of the main implant types included in the study were calculated (Table 5). Straumann had the highest fracture rate $(2.11 \%)$ among the implant types, giving Straumann SLA implants had the overall worse prognosis concerning implant fracture even including machined grade 1 implants. Straumann SLA implants were more commonly placed in bruxing patients than were Nobel turned or TiUnite implants in the entire 
material (Table 6), but this was not so in case of narrow implants where the modern implants actually fractured (Table 7). Despite this, in the narrow group $7.31 \%$ of Straumann implants fractured cf. $1.1 \%$ of turned and no TiUnite implants.

Table 8 shows the life table for implant fracture. Half of the occurrences of fractured implants happened between 2 and 8 years after implantation, and around one quarter of the fractures happened between 10 and 12 years after implant placement. There was a CSR of $98.8 \%$ after 34 years of follow-up. Figure 2 shows the Kaplan-Meier curve, showing that more than $98 \%$ of the implants did not present fractures after more than 35 years of follow-up.

\section{Discussion}

The present retrospective clinical study suggests that five factors could influence the incidence of implant fractures: grade of titanium, implant diameter, implant length, prosthetic work with cantilever, and bruxism.

Modern implants of titanium grade $3-4$ had $72.9 \%$ less probability of fracture than turned implants of grade 1 titanium. Grade 3-4 titanium may have close to $0.3 \%$ of iron instead of grade 1 titanium with only about $0.15 \%$ of iron. The iron contents are known to increase the strength of titanium considerably. ${ }^{10}$ In addition, one cannot exclude the possibility that surface treatment of modern implants may contribute somewhat to increased strength as well, not the least due to the compressive loads put upon these implants during manufacturing. ${ }^{11}$ One additional factor that may skew our material with respect to fracture percentage is the fact that titanium grade 1 implants were followed up for longer time than grade 3-4 modern implants.

Small diameter implants tend to fracture more easily than large ones, especially when placed in a posterior location. ${ }^{12}$ An implant $5 \mathrm{~mm}$ in diameter is three times stronger than a $3.75-\mathrm{mm}$ implant, and an implant $6 \mathrm{~mm}$ in diameter is six times stronger than a $3.75-\mathrm{mm}$ implant. ${ }^{13}$ Concerning the implant length, the higher probability of fracture with longer implants may be related to the fact the wider diameter (which presented lower probability of fracture) are not usually long. 
Surprisingly, the prevalence of implant fractures in the molar area was low. This is surprising because implants in premolar and molar regions are at a higher risk of fracture, especially if a cantilever on the prosthesis is present because it enhances the load on implants with either vertical or lateral forces. ${ }^{14}$ However, implants placed in the premolar region had the highest percentage of fracture among all regions. The reason for that was the fact that most full-arch prostheses were supported by implants placed until first- or second-premolar region, with no implants in the molar region. And here the prosthesis cantilever may play a significant role as the etiological factor of the implant fractures. In a photoelastic model study evaluating the effect of cantilever length on stress transfer by implant-supported prostheses ${ }^{15}$ it was observed that the highest stresses were located at the ridge crest on the distal surface of the distal implant for all cantilever lengths. As already mentioned, implants placed in the premolar region were most often the most distal implant in the present study. Still in this photoelastic study, ${ }^{15}$ apical stresses at the most distal implant developed in reciprocation to the effect of the distal tipping force on the cantilever, and there were disproportionate increases in maximum stress with increasing cantilever length. The presence of a cantilever greatly increases the stress, with peak stress points always located on the most distal implant. ${ }^{16}$

There was an 1,819.5\% higher probability of presenting an implant fracture in bruxers in comparison to non-bruxers. Implant fracture has been associated with parafunction. A parafunctional occlusal habit can contribute to the potential overload, as load magnitude, duration, frequency, and direction are increased by such activity. ${ }^{3,17,18}$ Six of the eight fractured implants in the study of Balshi ${ }^{19}$ supported posterior prostheses and all eight fractured implants occurred in patients with parafunctional habits. The results of the clinical study of Chrcanovic et al. ${ }^{3}$ suggest that bruxism may be an important contributor to the rate of mechanical complications in implant-supported restorations, as well as for a higher prevalence of implant fracture. The study compared groups of bruxers and non-bruxers having the same number of patients $(n=98)$ with the same total number of 
implants $(n=427)$ equally distributed between them. Bruxers presented 16 fractured implants, whereas non-bruxers did not present any case of implant fracture.

Straumann SLA implants had the worst prognosis concerning implant fracture possibly related to the design of the tissue-level implant system with an internal implant-abutment connection. ${ }^{20}$ The alveolar crest is often located in an area where the implant walls show minimum thickness. As a consequence, lateral bending moments act on the implant during function, which in turn leads to metal fatigue. ${ }^{12}$ It may be argued that the area of the internal connection forms a predestined site for implant fracture as pointed out by Shemtov-Yona et al., ${ }^{21}$ who found fractures occurring where thin metal cross sections and sharp notches coexisted. Therefore, implants with an external connection might be advantageous from that point of view. When only narrow implants were considered, as only narrow SLA implants fractured, there were no statistically significant difference in the distribution of implants between bruxers and non-bruxers for SLA versus Nobel turned $(p=0.493)$ and for SLA versus Nobel MK III TiUnite $(p=0.382)$. This suggests that narrow SLA implants may be subjected to more fractures when compared to narrow implants of other systems.

In the present paper we have noticed that the very great majority of fractures of modern surface enlarged implants occur with narrow implants at least over a follow up time of 2 to 8 years. Whether longer terms of follow ups will result in fractures also of implants of average diameter is unknown. However, it must be observed that the turned implants where we have interpreted $0.5 \%$ of noticed fractures of implants of average dimensions to depend on the known greater weakness of grade 1 titanium cf. higher grades at the same time are the implants followed up for the longest time of all. At the clinic in Malmö turned implants were the only ones used until the mid-1990s when other designs started to grow in numbers.

Because the patients in this study were not prospectively followed, it was not always possible to investigate whether marginal bone resorption developed before or after the fractures. Any significant bone loss at the crestal level would increase the unsupported coronal length of the implant, increasing the crown to implant ratio, resulting in the fixture becoming more at risk to 
bending forces..$^{22}$ It is unclear whether marginal bone loss is a cause or an effect of implant fracture, or if they are both consequences of unfavorable loading. ${ }^{23}$

Stress caused by screw joint connections to the implants from an ill-fitting prosthetic framework can result in constant shear load on the implant, predisposing it to fracture. Frequently, loosening of the screw(s) on the supraimplant component precedes implant fracture and may be a warning sign that the framework needs re-evaluation. ${ }^{19}$ Some studies have shown implant fracture in partially edentulous fixed prostheses occurs with older, less passively fitting prostheses. ${ }^{24-27}$ Misfit of the prosthesis framework could not be systematically analyzed in this study. However, the degree of misfit may be considered to be randomly distributed and therefore can be regarded as an independently-acting additional load factor.

The limitations of the present study include the fact that this is a retrospective study, which inherently results in flaws, manifested by gaps in information and incomplete records. Moreover, the implant primary stability was not analyzed, as well as crown-to-implant ratio, loosening of prosthesis screw and accuracy of fit restoration, and marginal bone loss.

\section{Conclusions}

According to the results of the present retrospective clinical study, it is suggested that five factors could influence the incidence of implant fractures: grade of titanium, implant diameter, implant length, prosthetic work with cantilever, and bruxism. 


\section{Acknowledgements}

Funding and support: This work was supported by research funds from the Oral Health Related Research by Region Skåne (Odontologisk Forskning i Region Skåne, OFRS 414321), Sweden, and from the Scientific Research Council of Sweden (Vetenskapsrådet, Dnr 2015-02971). This work was supported by Folktandvården AB, Region Skåne, Sweden.

Trial registration at the U.S. National Institutes of Health (clinicaltrials.gov): NCT02369562

Declaration of conflicting interests: There are no conflicts of interest to declare.

\section{References}

1. Velasquez-Plata D, Lutonsky J, Oshida Y, Jones R. A close-up look at an implant fracture: a case report. Int J Periodontics Restorative Dent 2002; 22: 483-491.

2. Traini T, De Paoli S, Caputi S, lezzi G, Piattelli A. Collagen fiber orientation near a fractured dental implant after a 5-year loading period: case report. Implant Dent 2006; 15: 70-76.

3. Chrcanovic BR, Kisch J, Albrektsson T, Wennerberg A. Bruxism and dental implant treatment complications: a retrospective comparative study of 98 bruxer patients and a matched group. Clin Oral Implants Res 2017; 28: e1-e9.

4. Goodacre CJ, Kan JY, Rungcharassaeng K. Clinical complications of osseointegrated implants. J Prosthet Dent 1999; 81: 537-552.

5. Brånemark PI, Hansson BO, Adell R, Breine U, Lindström J, Hallen O, Ohman A. Osseointegrated implants in the treatment of the edentulous jaw. Experience from a 10-year period. Scand J Plast Reconstr Surg Suppl 1977; 16: 1-132.

6. Levine RA, Clem DS, 3rd, Wilson TG, Jr., Higginbottom F, Solnit G. Multicenter retrospective analysis of the ITI implant system used for single-tooth replacements: results of loading for 2 or more years. Int J Oral Maxillofac Implants 1999; 14: 516-520. 
7. Lekholm U, Zarb GA. Patient selection and preparation In: Brånemark PI, Zarb GA, Albrektsson Ts, eds. Proceedings of the Tissue integrated prostheses: osseointegration in clinical dentistry. Quintessence Publishing Company, 1985: 199-209.

8. Lobbezoo F, Ahlberg J, Glaros AG, Kato T, Koyano K, Lavigne GJ, de Leeuw R, Manfredini D, Svensson P, Winocur E. Bruxism defined and graded: an international consensus. J Oral Rehabil 2013; 40: 2-4.

9. AASM. International Classification of Sleep Disorders, Revised: Diagnostic and Coding Manual. American Academy of Sleep Medicine Chicago

10. Albrektsson T, Brånemark PI, Hansson HA, Kasemo B, Larsson K, Lundström I, McQueen DH, Skalak R. The interface zone of inorganic implantsIn vivo: Titanium implants in bone. Annals of Biomedical Engineering 1983; 11: 1-27.

11. Gil FJ, Planell JA, Padros A. Fracture and fatigue behavior of shot-blasted titanium dental implants. Implant Dent 2002; 11: 28-32.

12. Tagger Green N, Machtei EE, Horwitz J, Peled M. Fracture of dental implants: literature review and report of a case. Implant Dent 2002; 11: 137-143.

13. Siddiqui AA, Caudill R. Proceedings of the 4th International Symposium on Implant Dentistry: Focus on Esthetics. San Diego, California, January 27-29, 1994. Abstracts. J Prosthet Dent 1994; 72: 623-634.

14. Shackleton JL, Carr L, Slabbert JC, Becker PJ. Survival of fixed implant-supported prostheses related to cantilever lengths. J Prosthet Dent 1994; 71: 23-26.

15. White SN, Caputo AA, Anderkvist T. Effect of cantilever length on stress transfer by implantsupported prostheses. J Prosthet Dent 1994; 71: 493-499.

16. Silva GC, Mendonca JA, Lopes LR, Landre J, Jr. Stress patterns on implants in prostheses supported by four or six implants: a three-dimensional finite element analysis. Int J Oral Maxillofac Implants 2010; 25: 239-246. 
17. Chrcanovic BR, Albrektsson T, Wennerberg A. Bruxism and Dental Implants: A Meta-Analysis. Implant Dent 2015; 24: 505-516.

18. Chrcanovic BR, Kisch J, Albrektsson T, Wennerberg A. Bruxism and dental implant failures: a multilevel mixed effects parametric survival analysis approach. J Oral Rehabil 2016; 43: 813-823.

19. Balshi TJ. An analysis and management of fractured implants: a clinical report. Int J Oral Maxillofac Implants 1996; 11: 660-666.

20. Karl M, Krafft T, Kelly JR. Fracture of a narrow-diameter roxolid implant: clinical and fractographic considerations. Int J Oral Maxillofac Implants 2014; 29: 1193-1196.

21. Shemtov-Yona K, Rittel D, Machtei EE, Levin L. Effect of dental implant diameter on fatigue performance. Part II: failure analysis. Clin Implant Dent Relat Res 2014; 16: 178-184.

22. Virdee P, Bishop K. A review of the aetiology and management of fractured dental implants and a case report. Br Dent J 2007; 203: 461-466.

23. Eckert SE, Meraw SJ, Cal E, Ow RK. Analysis of incidence and associated factors with fractured implants: a retrospective study. Int J Oral Maxillofac Implants 2000; 15: 662-667.

24. Adell R, Lekholm U, Rockler B, Brånemark PI. A 15-year study of osseointegrated implants in the treatment of the edentulous jaw. Int J Oral Surg 1981; 10: 387-416.

25. Carr AB, Stewart RB. Full-arch implant framework casting accuracy: preliminary in vitro observation for in vivo testing. J Prosthodont 1993; 2: 2-8.

26. Meijer HJ, Kuiper JH, Starmans FJ, Bosman F. Stress distribution around dental implants: influence of superstructure, length of implants, and height of mandible. J Prosthet Dent 1992; 68: 96-102.

27. Watanabe F, Uno I, Hata Y, Neuendorff G, Kirsch A. Analysis of stress distribution in a screwretained implant prosthesis. Int J Oral Maxillofac Implants 2000; 15: 209-218. 
Table 1. Distribution of implants with respect to the different kinds of prosthetic restorations. The number between parentheses represents the number of fractured implants.

\begin{tabular}{lccccc}
\hline Implant & $\begin{array}{c}\text { Single } \\
\text { crown }\end{array}$ & $\begin{array}{c}\text { Partial fixed, } \\
2-6 \text { units }\end{array}$ & $\begin{array}{c}\text { Partial fixed, } \\
7-10 \text { units }\end{array}$ & $\begin{array}{c}\text { Full-arch } \\
\text { fixed }\end{array}$ & $\begin{array}{c}\text { Overdent } \\
\text { ure }\end{array}$ \\
\hline Nobel turned* & $400(6)$ & $1278(7)$ & $186(1)$ & $3665(14)$ & $166(2)$ \\
Nobel MKIII TiUnite* & 689 & $906(1)$ & 124 & 914 & 111 \\
Nobel Active & 79 & 32 & 4 & 6 & 2 \\
Astra TiOblast* & 54 & 104 & 18 & $208(4)$ & 4 \\
Astra Osseospeed & 74 & $62(2)$ & 0 & $72(1)$ & 2 \\
Straumann SLA & 56 & $118(2)$ & 13 & $92(4)$ & 6 \\
Straumann Bone Level & 33 & 6 & 0 & 0 & 0 \\
Frialit-2 & 38 & 5 & 0 & 0 & 0 \\
XiVE & 168 & 21 & 4 & 30 & 0 \\
Begos Semados & 26 & 44 & 22 & 58 & 2 \\
Other* & 66 & 24 & 0 & 10 & 0 \\
TOTAL* & $\mathbf{1 6 8 3 ( 6 )}$ & $\mathbf{2 6 0 0 ( 1 2 )}$ & $\mathbf{3 7 1 ( 1 )}$ & $\mathbf{5 0 5 5 ( 2 3 )}$ & $\mathbf{2 9 3}$ (2) \\
\hline
\end{tabular}

* The information for prosthesis type is unknown for a variable number of implants.

Table 2. Implant location and cantilever.

\begin{tabular}{lcccccc}
\hline Region & \multicolumn{3}{c}{ Presence of cantilever adjacent to an implant* - $\mathbf{n}$ (\%) } & \multirow{2}{*}{ Total* } \\
\cline { 2 - 6 } & No & Adjacent & $\begin{array}{c}\text { 1 tooth } \\
\text { away }\end{array}$ & $\begin{array}{c}\text { 2 teeth } \\
\text { away }\end{array}$ & $\begin{array}{c}\text { Half-tooth } \\
\text { cantilever }\end{array}$ & \\
\hline Incisive & $2223(63.3)$ & $73(2.1)$ & $441(12.5)$ & $746(21.2)$ & $31(0.9)$ & $3514(100)$ \\
Canine & $674(30.7)$ & $609(27.7)$ & $332(15.1)$ & $553(25.2)$ & $29(1.3)$ & $2197(100)$ \\
Premolar & $1569(50.8)$ & $1233(39.9)$ & $146(4.7)$ & $29(0.9)$ & $110(4.3)$ & $3087(100)$ \\
Molar & $520(80.5)$ & $52(8.0)$ & $28(4.3)$ & $18(2.8)$ & $28(4.3)$ & $646(100)$ \\
Total & $4986(52.8)$ & $1967(20.8)$ & $947(10.0)$ & $1346(14.3)$ & $198(2.1)$ & $9444(100)$ \\
\hline
\end{tabular}

* The information is unknown for a variable number of implants

Table 3. Distribution of implants and fractures according to different implant diameter ranges.

\begin{tabular}{|c|c|c|c|}
\hline & \multicolumn{3}{|c|}{ Implant fractures/total number of implants (\% fracture) } \\
\hline & \multicolumn{3}{|c|}{ Implant diameter* } \\
\hline & $3.00-3.50 \mathrm{~mm}$ & $3.70-4.10 \mathrm{~mm}$ & $4.20-5.00 \mathrm{~mm}$ \\
\hline Nobel turned & $1 / 91(1.10)$ & $29 / 5628(0.52)$ & $0 / 27(0)$ \\
\hline Nobel MKIII TiUnite & $0 / 135(0)$ & $1 / 2631(0.04)$ & $0 / 17(0)$ \\
\hline Nobel Active & $0 / 88(0)$ & $0 / 1(0)$ & $0 / 34(0)$ \\
\hline Astra TiOblast & $4 / 313(1.28)$ & $0 / 40(0)$ & $0 / 38(0)$ \\
\hline Astra Osseospeed & $3 / 143(2.10)$ & $0 / 47(0)$ & $0 / 20(0)$ \\
\hline Straumann SLA & $6 / 82(7.31)$ & $0 / 192(0)$ & $0 / 11(0)$ \\
\hline Straumann Bone Level & $0 / 20(0)$ & $0 / 19(0)$ & $0 / 0(0)$ \\
\hline Frialit-2 & $0 / 16(0)$ & $0 / 18(0)$ & $0 / 9(0)$ \\
\hline XiVE & $0 / 134(0)$ & $0 / 86(0)$ & $0 / 3(0)$ \\
\hline Bego Semados & $0 / 6(0)$ & $0 / 146(0)$ & $0 / 0(0)$ \\
\hline Other & $0 / 10(0)$ & $0 / 65(0)$ & $0 / 27(0)$ \\
\hline TOTAL & $14 / 1038(1.35)$ & $30 / 8873(0.34)$ & $0 / 186(0)$ \\
\hline
\end{tabular}

* For two implants the diameter is unknown. 
Table 4. Risk factor analysis for implant fracture using a generalized estimating equations (GEE) logistic regression model (forced entry method), at the implant-level (OR - odds ratio; $\mathrm{Cl}-$ confidence interval).

\begin{tabular}{|c|c|c|c|}
\hline Factor & Fracture/non-fracture* (\%) & OR $(95 \% \mathrm{Cl})$ & $P$-value \\
\hline \multicolumn{4}{|l|}{ Grade of titanium** } \\
\hline Grade 1 & $30 / 5718(0.5)$ & 1 & \\
\hline Grade 3-4 & $14 / 4337(0.3)$ & $0.271(0.091,0.802)$ & 0.018 \\
\hline \multicolumn{4}{|l|}{ Implant diameter } \\
\hline Increase by $1 \mathrm{~mm}$ & - & $0.031(0.002,0.410)$ & 0.008 \\
\hline \multicolumn{4}{|l|}{ Implant length } \\
\hline Increase by $1 \mathrm{~mm}$ & - & $1.223(1.047,1.429)$ & 0.011 \\
\hline \multicolumn{4}{|l|}{ Location } \\
\hline Maxilla & $27 / 5749(0.5)$ & 1 & \\
\hline Mandible & $17 / 4306(0.4)$ & $0.327(0.106,6.134)$ & 0.836 \\
\hline Anterior & $25 / 6067(0.4)$ & 1 & \\
\hline Posterior & $19 / 3988(0.5)$ & $1.211(0.416,3.527)$ & 0.726 \\
\hline \multicolumn{4}{|l|}{ Bone quantity } \\
\hline$A$ & $2 / 1272(0.2)$ & 1 & \\
\hline B & $15 / 4692(0.3)$ & $1.643(0.382,7.056)$ & 0.504 \\
\hline C & $22 / 2802(0.8)$ & $4.708(0.922,24.032)$ & 0.062 \\
\hline D & $3 / 858(0.3)$ & $3.422(0.609,19.213)$ & 0.162 \\
\hline $\mathrm{E}$ & $1 / 169(0.6)$ & $7.718(0.935,63.685)$ & 0.058 \\
\hline \multicolumn{4}{|l|}{ Bone quality } \\
\hline 1 & $2 / 384(0.5)$ & 1 & \\
\hline 2 & $22 / 4251(0.5)$ & $0.529(0.068,4.094)$ & 0.542 \\
\hline 3 & $18 / 4517(0.4)$ & $0.259(0.035,1.930)$ & 0.187 \\
\hline 4 & $1 / 641(0.2)$ & $0.060(0.003,1.052)$ & 0.054 \\
\hline \multicolumn{4}{|l|}{ Bone grafting } \\
\hline No & $38 / 9486(0.4)$ & 1 & \\
\hline Yes & $6 / 568(1.0)$ & $2.785(0.918,8.447)$ & 0.070 \\
\hline \multicolumn{4}{|l|}{ Reoperation } \\
\hline No & 42/9883 (0.4) & 1 & \\
\hline Yes & $2 / 172(1.1)$ & $0.500(0.091,2.762)$ & 0.427 \\
\hline \multicolumn{4}{|l|}{ Prosthetic restoration } \\
\hline Single crown & 6/1676 (0.4) & 1 & \\
\hline Partial fixed, 2-6 units & $12 / 2588(0.5)$ & $0.892(0.165,4.829)$ & 0.895 \\
\hline $\begin{array}{l}\text { Partial fixed, 7-10 } \\
\text { units }\end{array}$ & $1 / 370(0.3)$ & $0.660(0.039,11.075)$ & 0.773 \\
\hline Full-arch fixed & 23/5032 (0.5) & $0.441(0.064,3.013)$ & 0.403 \\
\hline Overdenture & $2 / 291(0.7)$ & $0.756(0.051,11.303)$ & 0.839 \\
\hline \multicolumn{4}{|l|}{ Cantilever } \\
\hline No & $16 / 4970(0.3 \%)$ & 1 & \\
\hline Adjacent to cantilever & $14 / 1953(0.7 \%)$ & $3.476(1.198,10.088)$ & 0.022 \\
\hline 1 tooth away & $3 / 944(0.3 \%)$ & $1.225(0.280,5.367)$ & 0.787 \\
\hline 2 teeth away & $9 / 1337(0.7 \%)$ & $4.004(1.435,11.171)$ & 0.008 \\
\hline Half-cantilever & $2 / 196(1.0 \%)$ & $3.728(0.547,25.387)$ & 0.179 \\
\hline \multicolumn{4}{|l|}{ Connected to tooth } \\
\hline No & $42 / 9264(0.5)$ & 1 & \\
\hline Yes & $2 / 138(1.4)$ & $1.397(0.232,8.418)$ & 0.715 \\
\hline \multicolumn{4}{|l|}{ Number implants maxilla } \\
\hline Increase by 1 & - & $1.001(0.794,1.261)$ & 0.997 \\
\hline
\end{tabular}




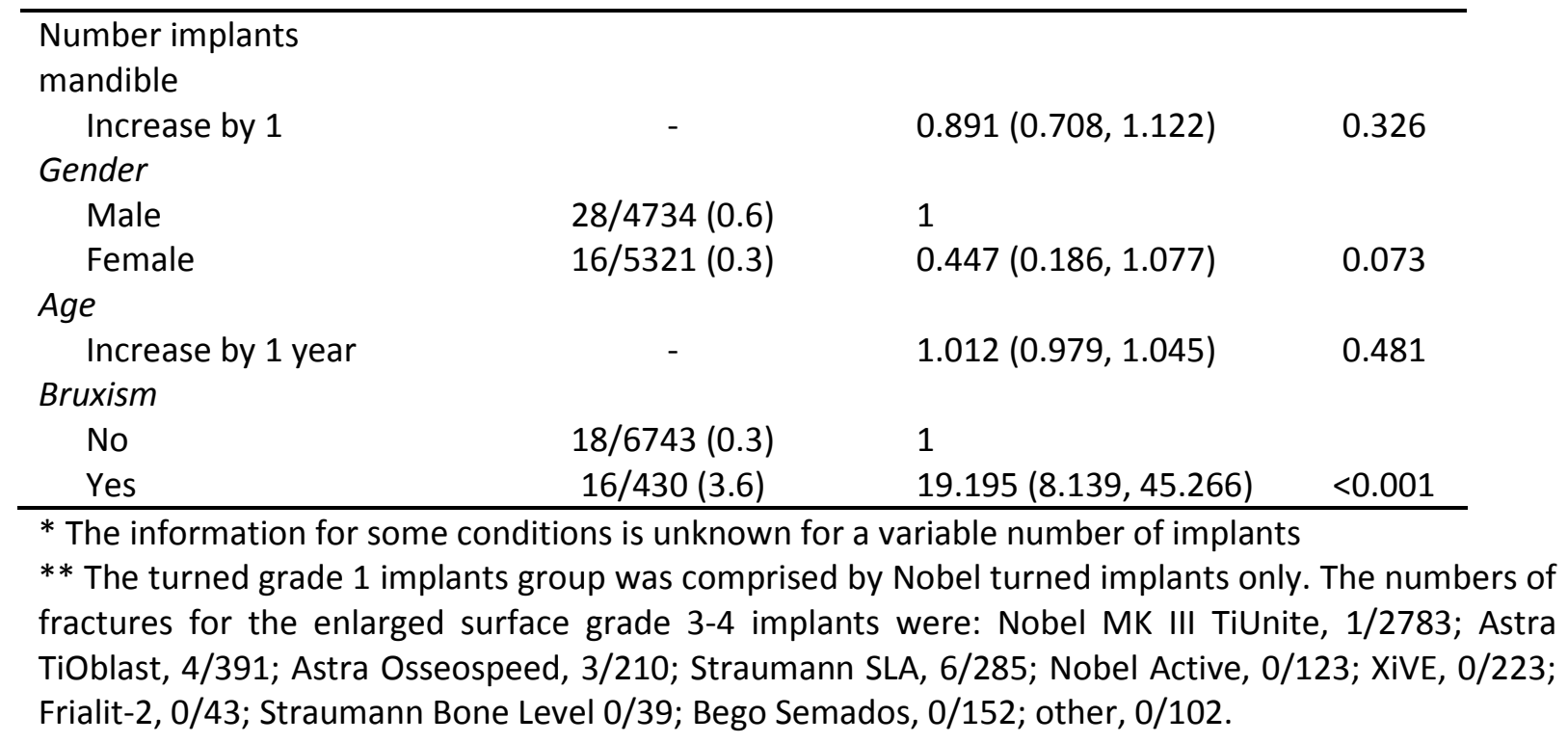

Table 5. Mean and standard deviation diameter and length of the main implant types included in the study, and the number (\%) of implants in some of the risk factors.

\begin{tabular}{|c|c|c|c|c|c|c|c|}
\hline Implant & $n$ & $\begin{array}{l}\text { Follow-up* } \\
\text { Mean } \pm S D\end{array}$ & $\begin{array}{l}\text { Diameter } \\
\text { Mean } \pm S D\end{array}$ & $\begin{array}{c}\text { Length } \\
\text { Mean } \pm S D\end{array}$ & $\begin{array}{c}\text { Bruxer** } \\
\text { Yes/total } \\
(\%)\end{array}$ & $\begin{array}{c}\text { Male** } \\
\text { Yes/total (\%) }\end{array}$ & $\begin{array}{c}\text { Bone quality } \\
1^{* *} \\
\text { Yes/total (\%) }\end{array}$ \\
\hline Nobel turned & 5748 & $155.5 \pm 89.1$ & $3.76 \pm 0.12$ & $13.08 \pm 2.63$ & $\begin{array}{c}192 / 3479 \\
(5.5)\end{array}$ & $2720 / 5748(47.3)$ & $272 / 5594(4.9)$ \\
\hline Nobel MKIII TiUnite & 2783 & $74.1 \pm 48.3$ & $3.74 \pm 0.14$ & $12.75 \pm 1.90$ & $\begin{array}{c}144 / 2372 \\
(6.1)\end{array}$ & $1338 / 2783(48.1)$ & 74/2707 (2.7) \\
\hline Nobel Active & 123 & $34.6 \pm 15.4$ & $3.68 \pm 0.47$ & $12.61 \pm 1.39$ & $\begin{array}{l}6 / 116 \\
(5.2)\end{array}$ & $54 / 123(43.9)$ & $2 / 123(1.6)$ \\
\hline Astra TiOblast & 391 & $121.5 \pm 66.7$ & $3.65 \pm 0.34$ & $12.60 \pm 2.16$ & $\begin{array}{c}18 / 296 \\
(6.1)\end{array}$ & 143/391 (36.6) & $18 / 386(4.7)$ \\
\hline Astra Osseospeed & 210 & $73.1 \pm 44.4$ & $3.68 \pm 0.40$ & $11.96 \pm 1.74$ & $\begin{array}{c}16 / 192 \\
(8.3)\end{array}$ & $103 / 210$ (49) & $3 / 203(1.5)$ \\
\hline Straumann SLA & 285 & $77.6 \pm 56.6$ & $3.89 \pm 0.40$ & $11.37 \pm 1.91$ & $\begin{array}{c}25 / 251 \\
(10)\end{array}$ & $128 / 285$ (44.9) & $7 / 268(2.6)$ \\
\hline Frialit-2 & 43 & $119.1 \pm 56.8$ & $3.80 \pm 0.41$ & $13.65 \pm 1.54$ & $0 / 23(0)$ & $26 / 43(60.5)$ & $1 / 41(2.4)$ \\
\hline XiVE & 223 & $95.0 \pm 33.1$ & $3.41 \pm 0.38$ & $13.52 \pm 1.55$ & $\begin{array}{c}9 / 178 \\
(5.1) \\
\end{array}$ & $105 / 223(47.1)$ & $5 / 221(2.3)$ \\
\hline
\end{tabular}

* In months

** The information for some conditions is unknown for a variable number of implants. 
Table 6. Significance of the difference between implants of different systems, for the factors listed in Table 5.

\begin{tabular}{|c|c|c|c|c|c|c|c|}
\hline & \multicolumn{7}{|c|}{$p$-value } \\
\hline & Fractures & $\begin{array}{c}\text { Follow- } \\
\text { up* }\end{array}$ & $\begin{array}{c}\text { Diamete } \\
r^{*}\end{array}$ & $\begin{array}{c}\text { Length } \\
*\end{array}$ & Bruxer & Male & $\begin{array}{c}\text { Bone } \\
\text { quality } 1\end{array}$ \\
\hline Turned vs. TiUnite & $<0.001+$ & $<0.001$ & $<0.001$ & $<0.001$ & $0.373+$ & $0.512+$ & $<0.001+$ \\
\hline Turned vs. Active & $0.529 \ddagger$ & $<0.001$ & $<0.001$ & 0.002 & $0.872 \dagger$ & $0.452+$ & $0.096+$ \\
\hline Turned vs. TiOblast & $0.168 \neq$ & $<0.001$ & $<0.001$ & $<0.001$ & $0.685+$ & $<0.001+$ & $0.860+$ \\
\hline Turned vs. Osseospeed & $0.109 \ddagger$ & $<0.001$ & $<0.001$ & $<0.001$ & $0.101+$ & $0.623+$ & $0.026+$ \\
\hline Turned vs. SLA & $0.006 \ddagger$ & $<0.001$ & $<0.001$ & $<0.001$ & $0.004^{\dagger}$ & $0.427+$ & $0.091+$ \\
\hline Turned vs. Frialit-2 & $0.799 \ddagger$ & 0.008 & $<0.001$ & 0.080 & $0.272 \ddagger$ & $0.085+$ & $0.402 \ddagger$ \\
\hline Turned vs. XiVE & $0.318 \ddagger$ & $<0.001$ & $<0.001$ & 0.004 & $0.792 \dagger$ & $0.945+$ & $0.075+$ \\
\hline Active vs. TiUnite & $0.958 \ddagger$ & $<0.001$ & $<0.001$ & 0.123 & $0.691+$ & $0.364+$ & $0.349 \ddagger$ \\
\hline Active vs. TiOblast & $0.334 \ddagger$ & $<0.001$ & 0.759 & 0.961 & $0.723+$ & $0.145+$ & $0.101 \ddagger$ \\
\hline Active vs. Osseospeed & $0.249 \ddagger$ & $<0.001$ & 0.556 & $<0.001$ & $0.297+$ & $0.364+$ & $0.624 \ddagger$ \\
\hline Active vs. SLA & $0.114 \ddagger$ & $<0.001$ & 0.034 & $<0.001$ & $0.125^{\dagger}$ & $0.851+$ & $0.423 \ddagger$ \\
\hline Active vs. Frialit-2 & No fractures & $<0.001$ & 0.287 & $<0.001$ & $0.330 \ddagger$ & $0.061+$ & $0.581 \ddagger$ \\
\hline Active vs. XiVE & No fractures & $<0.001$ & $<0.001$ & $<0.001$ & $0.865+$ & $0.570 \dagger$ & $0.514 \ddagger$ \\
\hline TiUnite vs. TiOblast & $0.001 \ddagger$ & $<0.001$ & $<0.001$ & 0.074 & $0.994+$ & $<0.001+$ & $0.037+$ \\
\hline TiUnite vs. Osseospeed & $0.001 \ddagger$ & 0.928 & $<0.001$ & $<0.001$ & $0.213+$ & $0.786+$ & $0.282 \dagger$ \\
\hline TiUnite vs. SLA & $<0.001 \ddagger$ & 0.878 & $<0.001$ & $<0.001$ & $0.017+$ & $0.308+$ & $0.907+$ \\
\hline TiUnite vs. Frialit-2 & $0.985 \ddagger$ & $<0.001$ & $<0.001$ & 0.002 & $0.239 \ddagger$ & $0.107+$ & $0.691 \ddagger$ \\
\hline TiUnite vs. XiVE & $0.926 \ddagger$ & $<0.001$ & $<0.001$ & $<0.001$ & $0.582+$ & $0.775+$ & $0.678+$ \\
\hline TiOblast vs. Osseospeed & $0.467 \ddagger$ & $<0.001$ & 0.144 & $<0.001$ & $0.340+$ & $0.003+$ & $0.048+$ \\
\hline TiOblast vs. SLA & $0.203 \ddagger$ & $<0.001$ & $<0.001$ & $<0.001$ & $0.093+$ & $0.029+$ & $0.178+$ \\
\hline TiOblast vs. Frialit-2 & $0.658 \ddagger$ & 0.922 & 0.347 & 0.001 & $0.250 \ddagger$ & $0.002+$ & $0.438 \ddagger$ \\
\hline TiOblast vs. XiVE & $0.164 \ddagger$ & $<0.001$ & $<0.001$ & $<0.001$ & $0.641+$ & $0.011+$ & $0.136+$ \\
\hline Osseospeed vs. SLA & $0.442 \ddagger$ & 0.828 & $<0.001$ & 0.001 & $0.558+$ & $0.362+$ & $0.306 \ddagger$ \\
\hline Osseospeed vs. Frialit-2 & $0.570 \ddagger$ & $<0.001$ & 0.873 & $<0.001$ & $0.152 \dagger$ & $0.172+$ & $0.523 \ddagger$ \\
\hline Osseospeed vs. XiVE & $0.113 \ddagger$ & $<0.001$ & $<0.001$ & $<0.001$ & $0.210+$ & $0.683+$ & $0.410 \ddagger$ \\
\hline SLA vs. Frialit-2 & $0.427 \ddagger$ & $<0.001$ & 0.093 & $<0.001$ & $0.100 \ddagger$ & $0.057+$ & $0.712+$ \\
\hline SLA vs. XiVE & $0.030 \ddagger$ & $<0.001$ & $<0.001$ & $<0.001$ & $0.064^{\dagger}$ & $0.626+$ & $0.804 \dagger$ \\
\hline Frialit-2 vs. XiVE & No fractures & 0.003 & $<0.001$ & 0.602 & $0.327 \ddagger$ & $0.108+$ & $0.644 \ddagger$ \\
\hline
\end{tabular}

*Mann-Whitney

† Pearson chi-squared test

¥ Fisher's exact test 
Table 7. Significance of the difference between the number of narrow implants placed in bruxers.

\begin{tabular}{lc}
\hline Narrow implants & $\begin{array}{c}\text { Number of narrow implants in } \\
\text { bruxers }\end{array}$ \\
\hline Turned vs. TiUnite & $0.704 \ddagger$ \\
Turned vs. Active & $0.378 \ddagger$ \\
Turned vs. TiOblast & $0.354 \ddagger$ \\
Turned vs. Osseospeed & $0.129 \ddagger$ \\
Turned vs. SLA & $0.493 \ddagger$ \\
Turned vs. Frialit-2 & $0.864 \ddagger$ \\
Turned vs. XiVE & $0.364 \ddagger$ \\
Active vs. TiUnite & $0.302 \ddagger$ \\
Active vs. TiOblast & $0.036 \ddagger$ \\
Active vs. Osseospeed & $0.006 \ddagger$ \\
Active vs. SLA & $0.114 \ddagger$ \\
Active vs. Frialit-2 & $*$ \\
Active vs. XiVE & $0.052 \ddagger$ \\
TiUnite vs. TiOblast & $0.204 \ddagger$ \\
TiUnite vs. Osseospeed & $0.047 \dagger$ \\
TiUnite vs. SLA & $0.382 \ddagger$ \\
TiUnite vs. Frialit-2 & $0.860 \ddagger$ \\
TiUnite vs. XiVE & $0.235 \ddagger$ \\
TiOblast vs. Osseospeed & $0.196 \dagger$ \\
TiOblast vs. SLA & $0.531 \ddagger$ \\
TiOblast vs. Frialit-2 & $0.696 \ddagger$ \\
TiOblast vs. XiVE & $0.563 \ddagger$ \\
Osseospeed vs. SLA & $0.194 \ddagger$ \\
Osseospeed vs. Frialit-2 & $0.536 \ddagger$ \\
Osseospeed vs. XiVE & $0.344 \dagger$ \\
SLA vs. Frialit-2 & $0.749 \ddagger$ \\
SLA vs. XiVE & $0.524 \ddagger$ \\
Frialit-2 vs. XiVE & $0.690 \ddagger$ \\
\hline T Pearson chi-squared test \\
\end{tabular}

† Pearson chi-squared test

¥ Fisher's exact test

* Both with no narrow implants in bruxers 
Table 8. Life table for implant fracture.

\begin{tabular}{cccccccc}
\hline $\begin{array}{c}\text { Interval } \\
\text { start } \\
\text { time } \\
\text { (years) }\end{array}$ & $\begin{array}{c}\text { Number } \\
\text { entering } \\
\text { interval }\end{array}$ & $\begin{array}{c}\text { Number } \\
\text { withdrawing } \\
\text { during } \\
\text { interval }\end{array}$ & $\begin{array}{c}\text { Number } \\
\text { exposed } \\
\text { to risk }\end{array}$ & $\begin{array}{c}\text { Number } \\
\text { of } \\
\text { terminal } \\
\text { events } \\
\text { (implant } \\
\text { fracture) }\end{array}$ & $\begin{array}{c}\text { Proportion } \\
\text { terminating }\end{array}$ & $\begin{array}{c}\text { Proportion } \\
\text { surviving }\end{array}$ & $\begin{array}{c}\text { Cumulative } \\
\text { proportion } \\
\text { surviving } \\
\text { at end of } \\
\text { interval }\end{array}$ \\
\hline 0 & 10099 & 1471 & 9363.5 & 3 & 0.000 & 1.000 & 1.000 \\
2 & 8625 & 1217 & 8016.5 & 9 & 0.001 & 0.999 & 0.999 \\
4 & 7399 & 1277 & 6760.5 & 5 & 0.001 & 0.999 & 0.998 \\
6 & 6117 & 964 & 5635.0 & 8 & 0.001 & 0.999 & 0.996 \\
8 & 5145 & 945 & 4672.5 & 2 & 0.000 & 1.000 & 0.996 \\
10 & 4198 & 951 & 3722.5 & 10 & 0.003 & 0.997 & 0.993 \\
12 & 3237 & 707 & 2883.5 & 3 & 0.001 & 0.999 & 0.992 \\
14 & 2527 & 674 & 2190.0 & 3 & 0.001 & 0.999 & 0.991 \\
16 & 1850 & 564 & 1568.0 & 0 & 0.000 & 1.000 & 0.991 \\
18 & 1286 & 369 & 1101.5 & 0 & 0.000 & 1.000 & 0.991 \\
20 & 917 & 254 & 790.0 & 0 & 0.000 & 1.000 & 0.991 \\
22 & 663 & 266 & 530.0 & 0 & 0.000 & 1.000 & 0.991 \\
24 & 397 & 199 & 297.5 & 1 & 0.003 & 0.997 & 0.988 \\
26 & 197 & 97 & 148.5 & 0 & 0.000 & 1.000 & 0.988 \\
28 & 100 & 82 & 59.0 & 0 & 0.000 & 1.000 & 0.988 \\
30 & 18 & 10 & 13.0 & 0 & 0.000 & 1.000 & 0.988 \\
32 & 8 & 3 & 6.5 & 0 & 0.000 & 1.000 & 0.988 \\
34 & 5 & 5 & 2.5 & 0 & 0.000 & 1.000 & 0.988 \\
\hline
\end{tabular}


Figure 1. Relation of an implant and a cantilever in the prosthetic work.

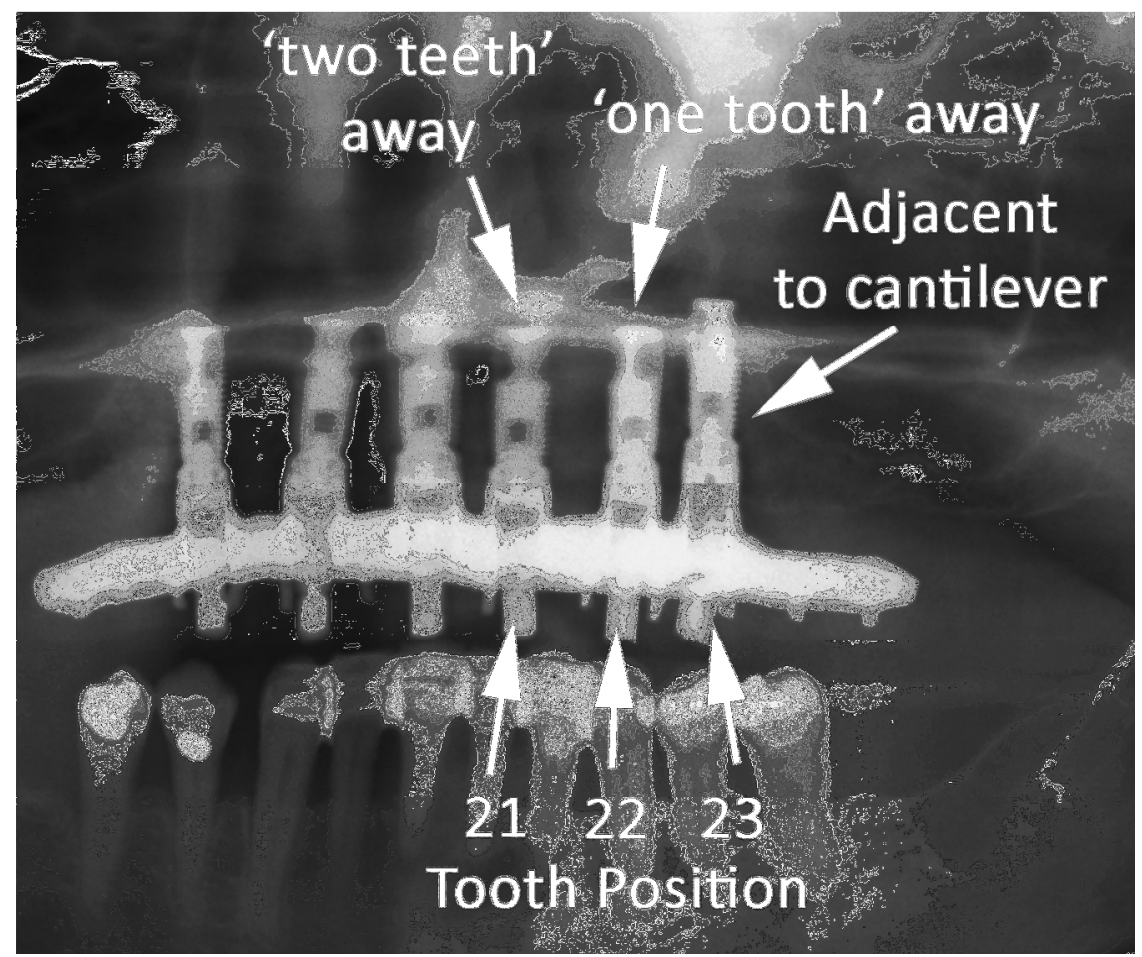

Figure 2. Kaplan-Meier curve for the event implant fracture.

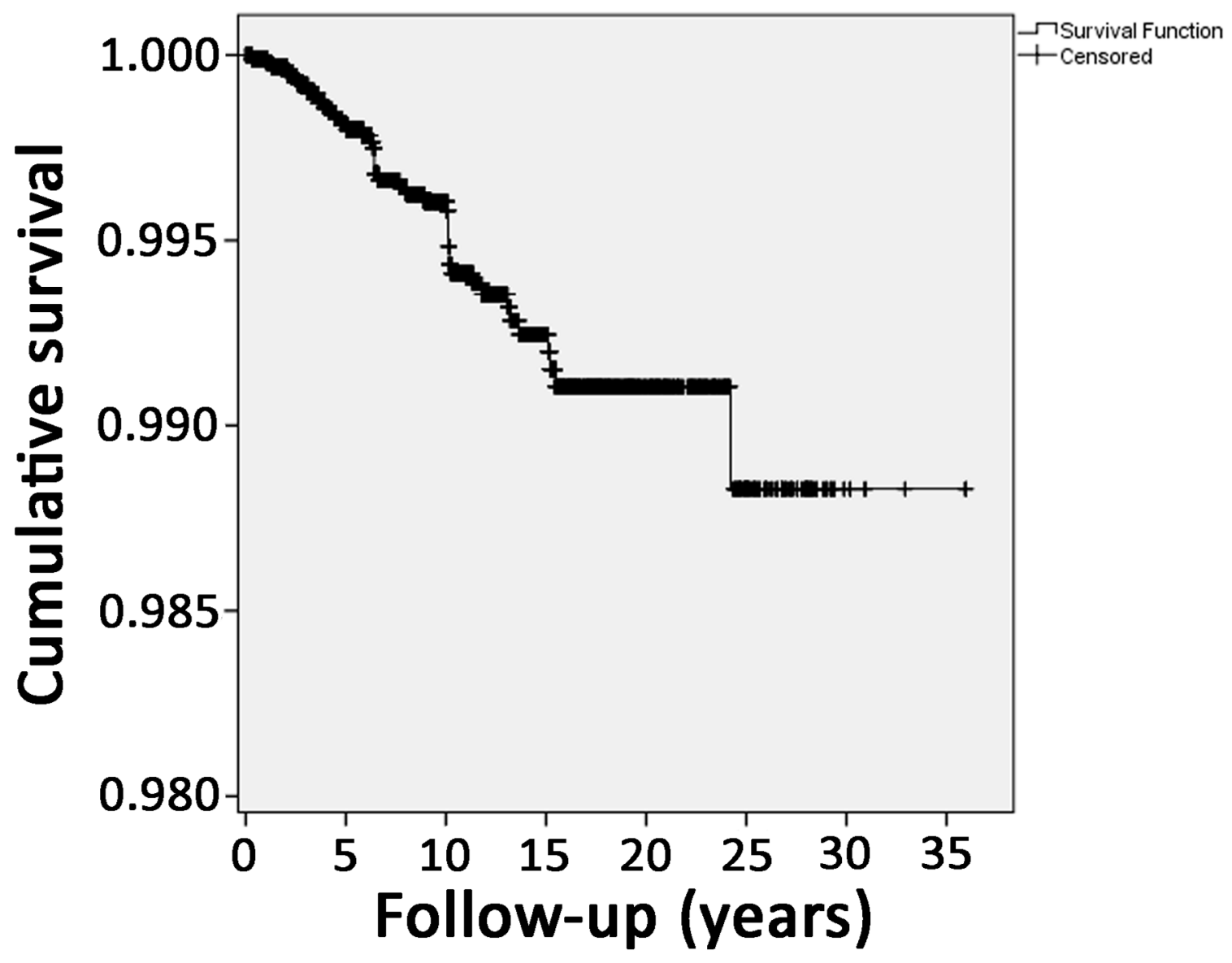

